\title{
Técnicas de geoprocessamento no suporte à análise da seca na microbacia do açude Jatobá II
}

\section{Geoprocessing techniques in supporting to drought analysis in the micro basin of dam Jatobá II}

\author{
Erickson Melo de Albuquerque ${ }^{1 *}$, Julio Mannuel Tavares Diniz ${ }^{2}$, Robson Felipe de Lima ${ }^{3}$, Fagner Nogueira Ferreira ${ }^{3}$, \\ Francisco das Chagas Silva ${ }^{3}$
}

\begin{abstract}
Resumo: O baixo índice pluviométrico é uma das principais características da região Semiárida do Brasil. Em particular, verifica-se nesta região uma redução significativa dos totais pluviométricos a partir do ano de 2012, ocasionando sérios danos aos níveis dos reservatórios. O açude Jatobá II, principal fonte hídrica para o município de Princesa Isabel-PB, vem apresentando uma queda considerável em seu volume. Este, por sua vez, foi declarado em situação de emergência no ano de 2015. Logo, fazendo uso de ferramentas de geoprocessamento, busca-se a partir do desenvolvimento da presente pesquisa analisar o real cenário da microbacia do açude Jatobá II. Foi utilizado o Índice de Vegetação por Diferença Normalizada IVDN para se obter informações sobre a vegetação na microbacia entre os anos de 2011 e 2013, além de imagens de alta resolução para identificar a redução na lâmina d'água do açude entre os anos de 2010 (ano de cheia) e 2014 (ano de seca). Dados hidrometeorológicos auxiliaram a perceber que os períodos com desvios negativos à pluviometria média climatológica coincidiram com a redução no volume do açude. Por fim, a população, a economia e o meio ambiente de Princesa Isabel estão a passar por dificuldades causadas pela seca.
\end{abstract}

Palavras-chaves: Desastre natural, índice de vegetação por diferença normalizada, sistema de informação geográfica, semiárido.

\begin{abstract}
The low rainfall is one of the main characteristics in the Brazil semiarid region. In particular, it is noted in this region a significant reduction of total rainfall from 2012, causing serious damages to the reservoir levels. The Jatobá II dam, main water source in Princesa Isabel municipality of Paraíba state, has shown a considerable fall in volume. This, in turn, was declared in emergency situation in 2015. Thus, using geoprocessing tools it aims from the development of the present research to analyze the real scenario in the micro watershed Jatobá II dam. Was used Vegetation Index Normalized Difference - NDVI to obtain information about vegetation in the micro watershed between the years 2011 and 2013, as well as high-resolution images to identify the reduction in water surface of the dam between 2010 (year of abundance) and 2014 (year of drought). Hydrometeorological data helped to realize that periods with negative deviations from the climatological average rainfall coincided with the reduction in reservoir volume. Finally, the population, the economy and the environment of Princesa Isabel are experiencing difficulties caused by drought.
\end{abstract}

Key words: Natural disaster, normalized difference vegetation index, geographic information system, semiarid.

\footnotetext{
*Autor para correspondência

Recebido para publicação em 20/09/2015; aprovado em 20/10/2015

${ }^{1}$ Mestre em Meteorologia-UFCG, Professor de Geoprocessamento-IFPB, Princesa Isabel-PB; (83) 9 9655 4382,erickson.melo@ gmail.com.

${ }^{2}$ Doutorando em Meteorologia, UFCG, julio_mannuel@hotmail.com

${ }^{3}$ Graduandos em Agronomia, CCTA, UFCG, Pombal-PB.
} 


\section{INTRODUÇÃO}

A água é um dos elementos fundamentais à vida. No meio ambiente, por meio do ciclo hidrológico, a água muda de estado físico e abastece os seres vivos que dela dependem. A falta de água é um problema grave à sobrevivência em algumas regiões do planeta. Devido a diversos fatores geográficos, meteorológicos e climatológicos essas regiões sofrem com a escassez de água ou déficit no ciclo hidrológico periodicamente, variando em intensidade (SOUSA JÚNIOR e LACRUZ, 2015).

A esse fenômeno ou desastre natural dá-se o nome de seca ou estiagem, porém, não existe um conceito preciso e universalmente aceito acerca do tema devido à complexidade em acurar a abrangência espaço-temporal e intensidade desse fenômeno. Castro et al (2003) diferenciam seca e estiagem segundo alguns parâmetros: atraso no início do período de chuvas por um prazo superior a 15 dias ou média pluviométrica mensal, nesse período, menor que $60 \%$ da climatologia local já caracterizam estiagem. Os autores ainda afirmam que a seca é uma estiagem prolongada. Sousa Júnior e Lacruz (2015) detalham, exemplificam e conceituam os diversos tipos de seca e suas consequências.

Uma das medidas adotadas pelo poder público para melhorar a convivência com a seca foi a criação de diversos órgãos técnicos e operacionais em diferentes esferas da administração pública. Estes, por sua vez, têm como objetivo elaborar e executar ações (contratação de carros pipa, perfuração de poços, construção de cisternas, etc.) a fim de amenizar os danos diretos deste fenômeno a população. Vale ressaltar que as medidas não contemplam somente o armazenamento da água, mas também o seu uso racional, melhor aproveitamento da energia solar, cartilhas educacionais e práticas para o desenvolvimento sustentável de modo geral.

A escassez hídrica é um fenômeno fortemente presente em toda a região semiárida do Brasil. Segundo o Instituto Nacional do Semiárido - INSA, a região semiárida abrange oito estados da região nordeste e o norte do estado de Minas Gerais, totalizando uma área aproximada de $980.133,79 \mathrm{~km}^{2}$. Em particular, uma parcela significativa dos municípios paraibanos está inserida na região semiárida, podendo-se destacar o município de Princesa Isabel.

O município de Princesa Isabel vem enfrentado uma seca severa nos últimos quatro anos $(2012,2013,2014$ e 2015), afetando consideravelmente o cotidiano dos habitantes, a economia e as atividades local. No ano de 2015, o Governo do Estado decretou no Diário Oficial do Estado situação de emergência em 170 municípios paraibanos, incluindo Princesa Isabel. O reservatório que abastece o município, chamado Jatobá II, foi um dos mais afetados, tendo o seu volume hídrico drasticamente reduzido e prejudicando o abastecimento da população.

Diante dos problemas ocasionados pela estiagem e seca, o sensoriamento remoto apresenta-se como uma tecnologia imprescindível ao diagnóstico socioambiental, estudo das consequências do fenômeno e apoio à elaboração de medidas paliativas e planejadas para diminuir os impactos causados. Esta constitui uma solução de baixo custo financeiro (no entanto, faz-se necessária mão de obra especializada) e uma alternativa oportuna para quando se é necessário abranger grandes áreas geográficas e registros temporais. Estes, por sua vez, são requisitos fundamentais para o estudo da seca, a exemplo da detecção de mudanças na cobertura do solo, vigor vegetativo e presença de água no ambiente, por meio de índices de vegetação (SOUSA JÚNIOR e LACRUZ, 2015).

No estudo da seca destaca-se o uso do Índice de Vegetação por Diferença Normalizada (Normalized Difference Vegetation Index - NDVI), que se trata de um índice obtido a partir de dados espectrais para explicitar as condições vegetativas, ou seja, o vigor vegetativo em cada pixel da imagem de forma numérica, variando de -1 a 1 .

Para subsidiar aos estudos de seca também é imprescindível o uso de dados hidrometeorológicos, tais como pluviométricos e limnimétricos. Na Paraíba, o órgão responsável pelo monitoramento hidrometeorológico é a Agência Executiva de Gestão das Águas - Aesa, que conta com uma rede densa de estações convencionais e automáticas no Estado e disponibiliza os dados coletados por meio do seu sítio na internet (http://www.aesa.pb.gov.br)

Diante do exposto, o objetivo do presente trabalho é analisar o cenário de seca entre 2010 e 2015, com base em dados geográficos e hidrometeorológicos, na microbacia do açude Jatobá II.

\section{MATERIAL E MÉTODOS}

\section{Área de Estudo}

O município de Princesa Isabel encontra-se a uma altitude média de 680 metros e dista cerca de $430 \mathrm{~km}$ da capital daquele estado. Em particular, limita-se a leste com o município de Tavares, a oeste com São José de Princesa, a norte com Nova Olinda e Pedra Branca e a sul com o Estado de Pernambuco. O clima deste município, de acordo com a classificação climática de Köppen, é quente semiúmido (Aw) e apresenta uma precipitação média anual em torno de 789,2 $\mathrm{mm}$. Por fim, de acordo com as estimativas populacionais do IBGE, o município possuía 22.734 habitantes no ano de 2014.

O único reservatório que abastece Princesa Isabel é o Açude Jatobá II. O volume hídrico deste tem diminuído significativamente desde o ano de 2010, principalmente devido à redução das chuvas na região nesse período. A água fornecida pelo açude é utilizada para diversos fins, tais como consumo humano e irrigação. Por se tratar do principal reservatório do município, muitas atividades são desenvolvidas no seu entorno e muitas delas utilizam essa água. Consequentemente, estas atividades geram alguns impactos que precisam ser identificados e mensurados para fins de preservação, o que é uma das demandas locais para uma gestão ambiental eficiente.

A microbacia do açude Jatobá II compreende uma área total de $66.030,33 \mathrm{~km}^{2}$, sendo que $51.068,49 \mathrm{~km}^{2}$ encontramse dentro dos limites municipais de Princesa Isabel. Na Figura 1, pode-se observar a localização do município de Princesa Isabel e a microbacia do açude Jatobá II, juntamente com a sua rede de drenagem e ponto exutório. Todos esses dados foram obtidos a partir de técnicas de geoprocessamento que serão detalhadas adiante. 
Figura 1.Localização da microbracia do açude Jatobá II, em Princesa Isabel, PB.

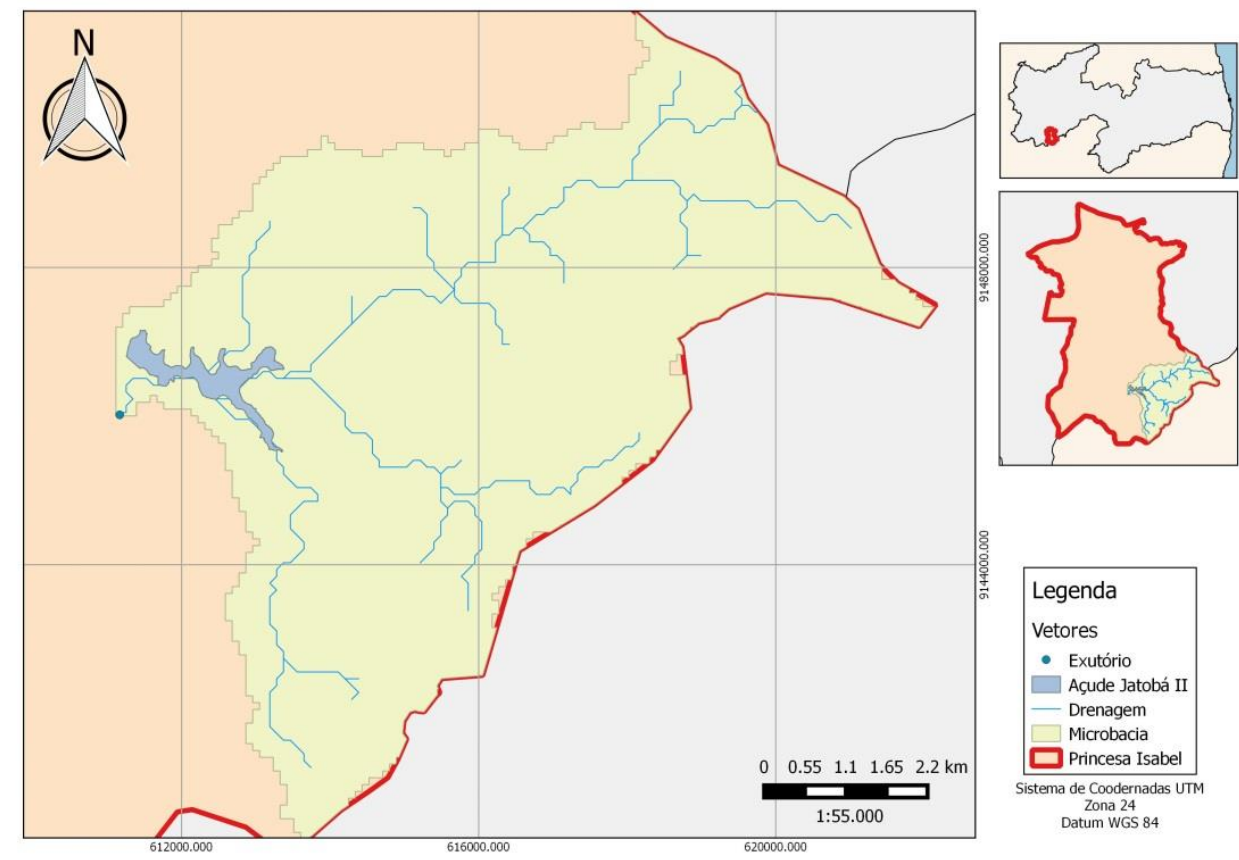

\section{Material}

O material utilizado pode ser dividido em softwares e dados. Os softwares utilizados foram o Google Earth Pro, para vetorização de imagens; o Quantum GIS 2.8.2 para edição vetorial e da tabela de atributos, utilização de ferramentas de geoprocessamento para recorte de dados, álgebra de mapas e produção do layout dos mapas finais, bem como a utilização de ferramentas auxiliares, como o TauDEM - TerrainAnalysisUsing Digital ElevationModels Versão 5 (USU, 2015) para a execução de algoritmos voltados à hidrologia e geomorfologia, a integração com o R (R-Project, 2015), para a geração de histogramas, e a biblioteca GDAL. Todos são softwares gratuitos.

Os dados geográficos utilizados foram: duas imagens do satélite RapidEye, fornecidas pelo Ministério do Meio Ambiente, datadas de 20 de junho de 2011 e 15 de junho de 2013, especificamente as bandas 3 e 5, referentes ao comprimento de onda do vermelho e do infravermelho próximo; Modelo Digital de Elevação (MDE) SRTM (USGS, 2000), contendo as altitudes da área de estudo; Arquivos vetoriais do tipo shape representativo dos limites municipais e estaduais e tipo KeyholeMarkupLanguage - KML, gerados no Google Earth Pro.
Além dos dados geográficos, foram obtidos dados alfanuméricos em formato de planilha digital contendo o monitoramento hidrometeorológico do açude Jatobá II por meio do acesso ao sítio da AESA na internet.

\section{Métodos}

A primeira etapa consistiu em fazer uso do TauDEM para delimitar a microbacia do açude Jatobá II. Para isso, cumpriram-se algumas etapas, esquematizada no fluxograma da Figura 2. O dado de entrada foi o MDE SRTM. Em seguida foi utilizada a ferramenta Pit Remove para remover pixels muito diferentes dos vizinhos; após isso foi obtida a imagem das direções de fluxo por meio do método D8 FlowDirection; o próximo produto obtido foi à área de contribuição utilizando o algoritmo D8 ContributingArea; em seguida, foi definido o exutório como limiar e definido o fluxo a partir dele (StreamDefinitionbyThreshold); e por fim, foi obtida a delimitação da microbacia, em formato matricial, e o rede de drenagem, em formato vetorial (SteamReachandWatershed).

Figura 2. Fluxograma de processamento para obtenção da delimitação da microbacia do açude Jatobá II

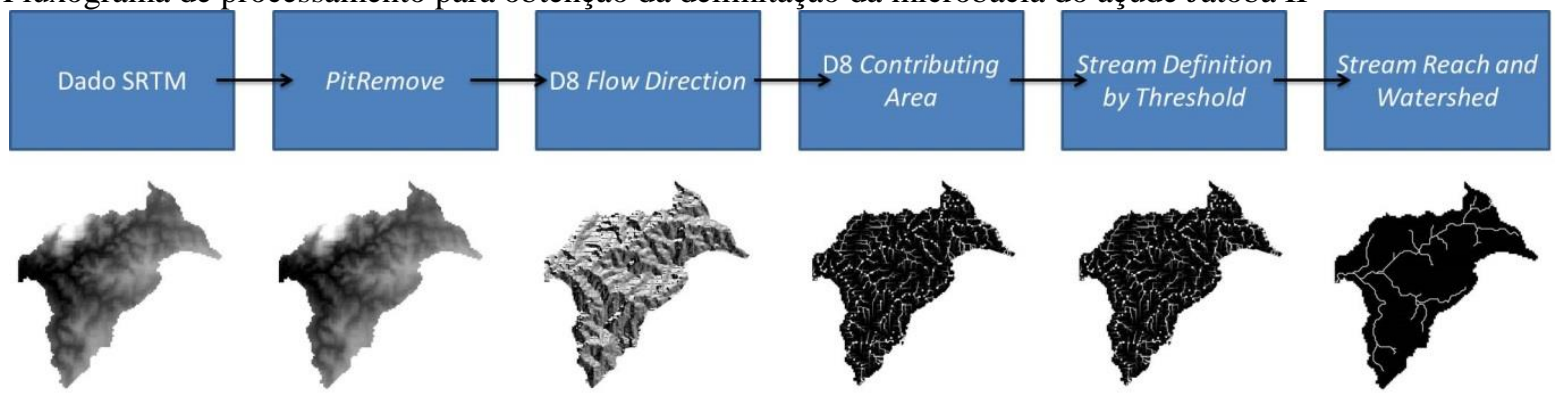

A etapa seguinte consistiu em vetorizar o contorno hídrico do açude Jatobá II no Google Earth Pro (2010 e 2014) utilizando a opção de visualizar imagens históricas para setembro de 2010 e a imagem mais recente disponível no 
software correspondente a setembro de 2014. Esses dados foram gerados no formato KML e importado ao Quantum GIS para serem sobrepostos às imagens produzidas e para o cálculo da área do açude nas referidas datas.

$\mathrm{O}$ processamento das imagens RapidEye se deu em conformidade com o que dizem Ponzoni et al (2012): calibração dos valores de radiância, de acordo com a Equação 1 (BLACKBRIDGE, 2015); Obtenção da reflectância monocromática (Equação 2) (idem); e cômputo do Índice de Vegetação por Diferença Normalizada (NormalizedDifferenceVegetation Index - NDVI), aplicando a Equação 3 (ROUSE et al, 1974).

$$
R A D(i)=D N * 0,01
$$

Em que: RAD(i) é a calibração radiométrica; DN é o nível digital; e 0,01 é o fator de escala radiométrica dado por Blackbridge (2015).

$$
R E F_{i}=R A D(i) \frac{\pi \times \text { SunDist }^{2}}{E A I_{i} \times \cos (\text { SolarZenith })}
$$

Em que: $\mathrm{REF}_{\mathrm{i}}$ é a reflectância monocromática; RAD(i) é o valor da radiância; SunDist é a distância Terra-Sol em Unidades Astronômicas (UA); EAI $_{\mathrm{i}}$ é a irradiância da exoatmosfera, segundo Blackbridge (2015); SolarZenith é o ângulo zenital solar, fornecido nos metadados da imagem.

$$
N D V I=\frac{\rho_{\text {nir }}-\rho_{\text {red }}}{\rho_{\text {nir }}+\rho_{\text {red }}}
$$

Em que: NDVI é o Índice de Vegetação por Diferença Normalizada; $\rho$ red $\neg$ é a reflectância na banda do vermelho; e nir $\neg$ é a reflectância na banda do infravermelho próximo. Conforme Ponzoniet et al (2012), valores negativos de NDVI correspondem a água; valores muito próximos de 0 correspondem a superfície não vegetada; e quanto mais próximo de 1, mais densa é a vegetação.

\section{RESULTADOS E DISCUSSÃO}

Observa-se nas imagens do NDVI obtidas que, entre aquelas datadas de junho de 2011 e junho de 2013, há decaimento do NDVI na microbacia do açude Jatobá II (Figura 3). De acordo com o NDVI apresentado, os tons de verde mais escuro (acima de 0,54 ), correspondem à vegetação vigorosa, enquanto os valores negativos correspondem à água. Na imagem de 20/06/2011, percebe-se uma maior presença de vegetação sobre a área, especialmente na zona norte da microbacia. Os tons azuis indicam a presença de água, a perceber pela localização do açude Jatobá II. O histograma dessa mesma imagem indica maior concentração de pixels com valores entre 0,50 e 0,75 , sendo o pico em aproximadamente $0,70 \mathrm{com}$ mais de 500 mil pixels.

Já a imagem relativa à 15/06/2013 mostrou menor presença de vegetação considerada vigorosa e houve maior frequência dos valores de NDVI intermediários $(0,24)$ sobre a microbacia, inclusive diminuindo a presença de pixels indicadores de presença de água, entre $-0,36$ e -0,05. A zona norte da microbacia permaneceu como a de maior concentração de vegetação. No histograma dessa imagem confirma-se a interpretação visual de decaimento no NDVI, já que há frequências distribuídas de modo menos discrepante dos pixels com valores entre 0,20 e 0,80, estando as maiores frequências acima de 150 mil pixels para os valores entre 0,30 e 0,70 .

Figura3. Imagens de NDVI e seus respectivos histogramas da microbracia do açude Jatobá II

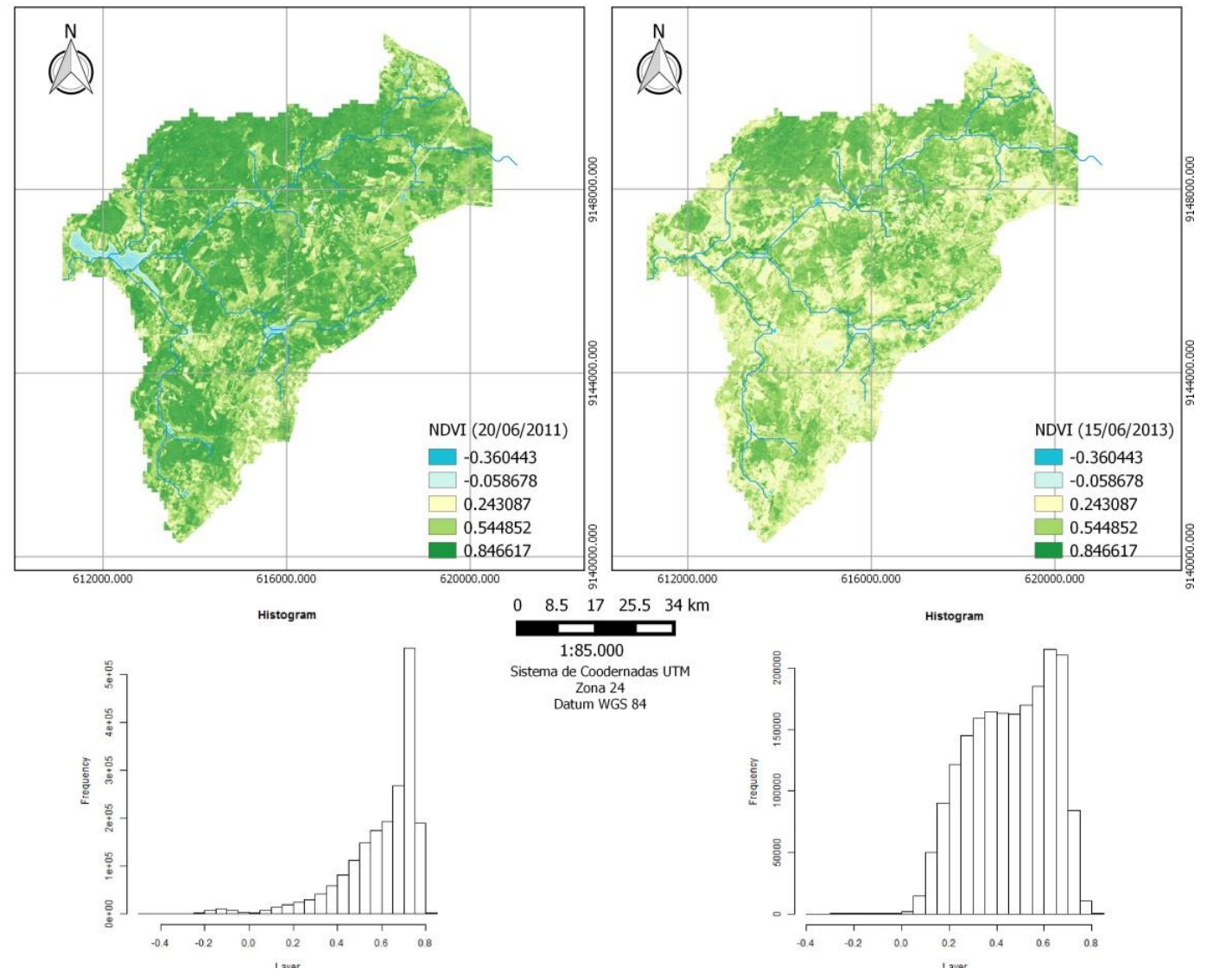


Em um intervalo de apenas dois anos ocorreu o decaimento do NDVI na área de estudos. Este fenômeno ao longo do tempo pode implicar em uma série de impactos ambientais, a exemplo da erosão do solo e desertificação, conforme mostram Rios \& Vale (2014) e Silva \& Machado (2014). De outro modo, o NDVI também pode ser utilizado para gerar índices de seca, que pode ser percebida a partir da anomalia do índice ao longo do tempo, tal como em Moreira et al (2015).

Uma das causas para o declínio do NDVI é a falta de chuvas, já que a água é um elemento fundamental para a saúde da vegetação (salvaguardando as especificidades das espécies), que por sua vez dependem da localização e do clima da região. De acordo com os resultados obtidos por Ávila et al (2009), na região sudeste a vegetação respondeu em aproximadamente 15 dias após a ocorrência de precipitação. Já na região semiárida do nordeste, Albuquerque et al (2014) encontraram significativa mudança no NDVI entre os períodos seco e chuvoso.

A Figura 4 mostra, para o período compreendido entre janeiro de 2010 e fevereiro de 2015, os desvios da pluviometria mensal com relação à climatologia de Princesa Isabel. As barras na cor verde (vermelha) indicam os meses em que a chuva foi maior (menor) que a climatologia daquele mês. Observa-se que, ao longo de todo o período analisado, foram poucos os meses que apresentaram chuvas acima da média. Logo, é nítida a predominância de meses com chuva abaixo da média, de modo que o período mais crítico esteve entre o fim de 2011 e começo de 2013 (desvio de -174,4 mm no mês de março do ano 2012).

Figura 4. Desvios da precipitação $(\mathrm{mm})$ em relação à climatologia de Princesa Isabel entre 2010 e 2015.

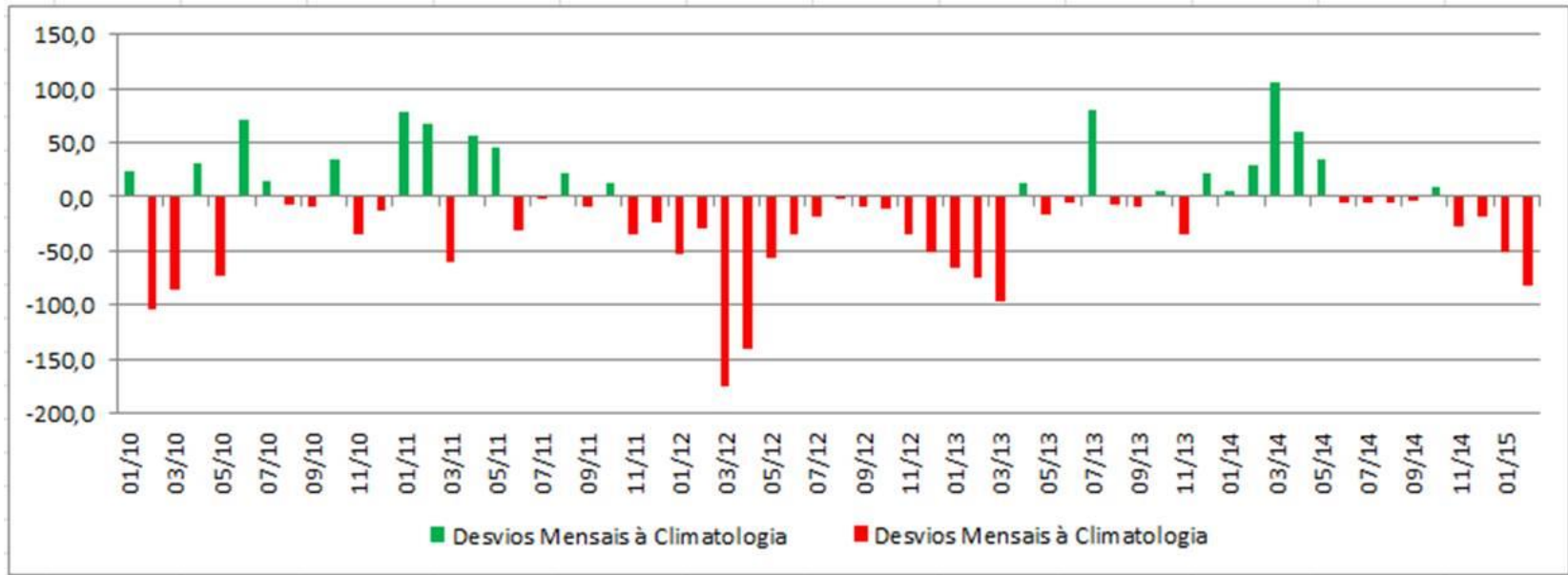

A chuva tem forte influência sobre a recarga hídrica dos reservatórios. A escassez de chuvas, que por sua vez ocorre desde o fim do ano de 2011, tem afetado consideravelmente o volume do açude Jatobá II. Como pode ser visto na Figura 5 , é evidente o contraste entre as lâminas de água de setembro de 2010 e setembro de 2014, apresentando aproximadamente $751,95 \mathrm{~km}^{2}$ e $192,17 \mathrm{~km}^{2}$, respectivamente.

Figura 5. Área de superfície hídrica do açude Jatobá em 09/2010 e 09/2014.
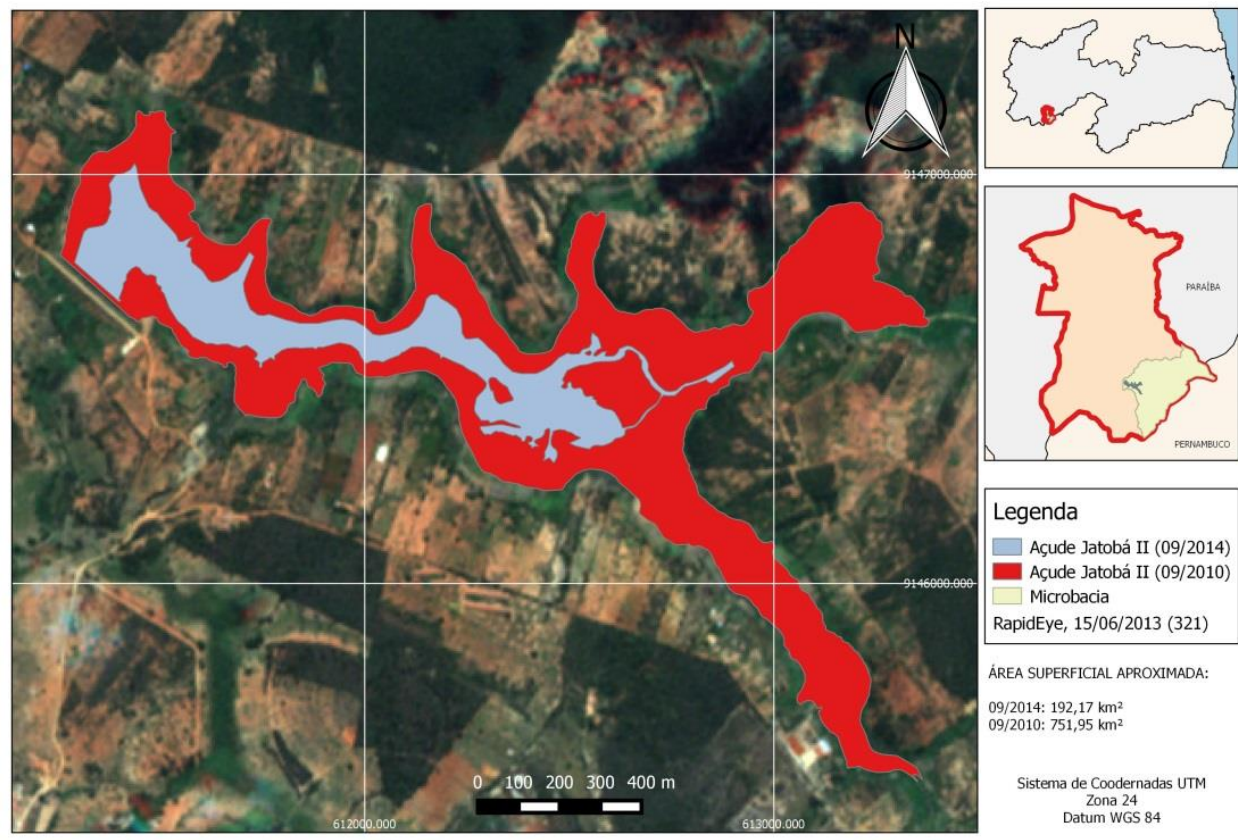
Na Figura 6 são apresentados os registros do volume do açude Jatobá II de fevereiro 2010 a julho de 2015. Neste período o açude atingiu sua capacidade máxima em maio de 2011. Desde então houve um decaimento contínuo até julho de 2015, reduzindo o volume hídrico de $6.443 .064 \mathrm{~m}^{3}$ para $77.940 \mathrm{~m}^{3}$, correspondente a $1,2 \%$ da capacidade máxima do açude.

Figura 6. Volume $\left(\mathrm{m}^{3}\right)$ do açude Jatobá II entre 2010 e 2015. Fonte: AESA.

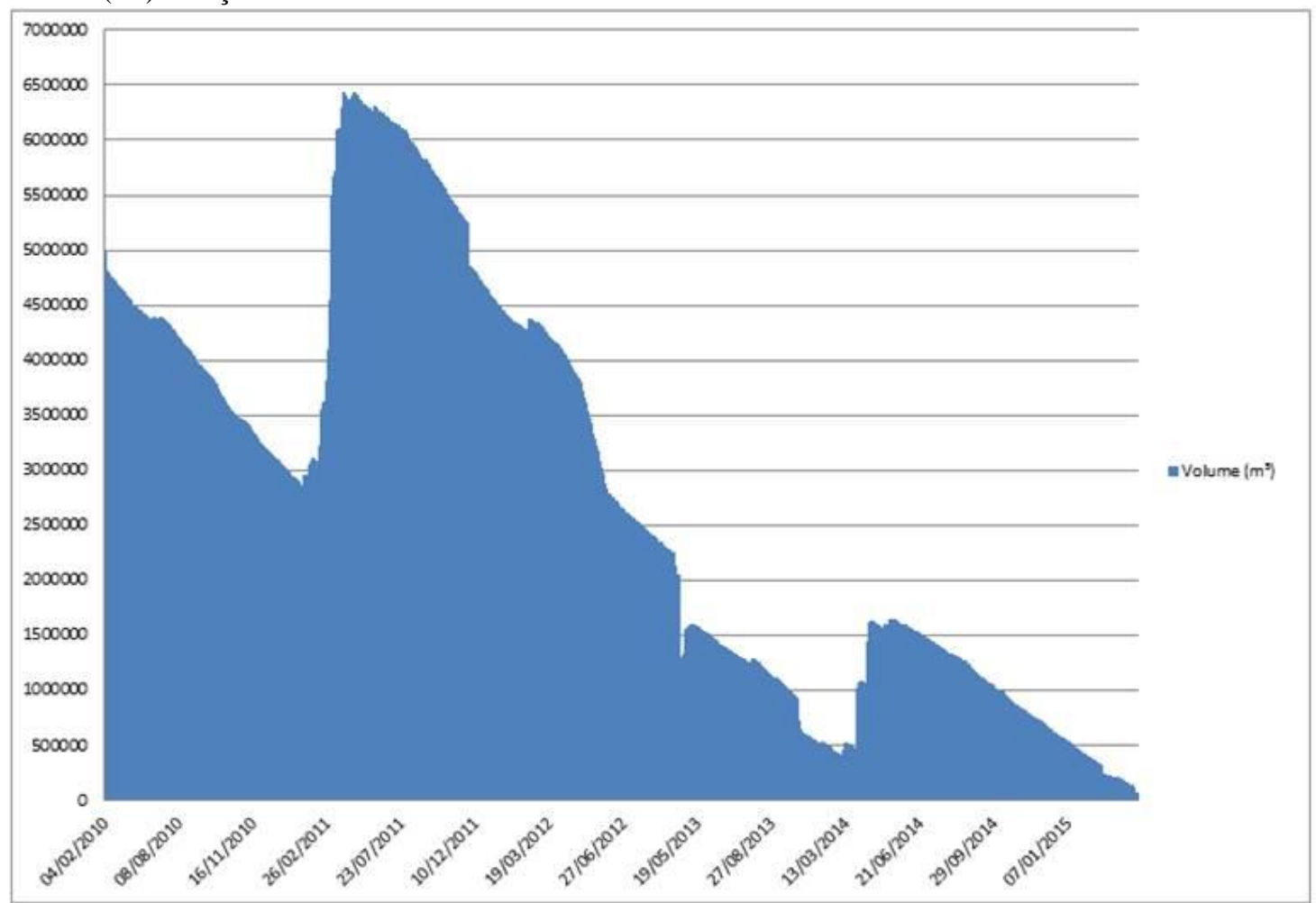

O padrão das chuvas no sertão paraibano é caracterizado anualmente pelas estações seca e chuvosa. Em Princesa Isabel, normalmente, maio é o mês que mais chove e isso coincide com os maiores volumes hídricos do açude. Entretanto, percebe-se que de 2010 para 2011, com a ocorrência das chuvas em torno da média, o açude conseguiu se recuperar. Este seria o comportamento esperado para manter o açude nas condições ideais. Após o pico em 2011, houve grande queda e uma pequena recuperação em junho de 2014, mas ainda muito aquém da capacidade total do reservatório.

A situação atual do açude Jatobá II é bastante preocupante para a gestão pública e para a população. Segundo a Companhia de Água e Esgoto da Paraíba (CAGEPA), a captação de água no açude é inviável devido ao seu baixo nível e a solução temporária para dar sequência ao abastecimento à população, adotada pela gestão municipal, foi a aquisição de caixas d'água e contratação de carros pipa. Em outras esferas administrativas existem medidas previstas para ser executadas, a exemplo da transposição do Rio São Francisco. Além disso, segue a esperança popular pelo retorno normal das chuvas à região.

\section{CONCLUSÕES}

Os dados geográficos e o processamento por meio de Sistema de Informação Geográfica - SIG produziram informações para embasar a análise, com a vantagem da demarcação da microbacia do açude Jatobá II via dados SRTM e obtenção do NDVI variando no espaço e no tempo. Os dados hidrometeorológicos atestaram a situação calamitosa do açude Jatobá II, que se encontrava com apenas $1,2 \%$ da capacidade total em julho de 2015. Neste contexto torna-se indispensável a busca por medidas alternativas para o abastecimento de água da população princesense.

Todavia, ressalta-se que a seca, enquanto fenômeno regional, irá causar maiores impactos sempre que não houver ou não for executado um planejamento adequado que torne possível a convivência com a mesma.

\section{REFERÊNCIAS BIBLIOGRÁFICAS}

ALBUQUERQUE, E. M ; ANDRADE, S. C. de P. ; MORAIS, H. F. de; DINIZ, J. M. T. ; SANTOS, C. A. C. dos. Análise do comportamento do NDVI e NDWI sob diferentes intensidades pluviométricas no município de Sousa-PB. Revista Estudos Geoambientais - Online. V. 01, n. 01, 2014

ÁVILA, A. M. H. de; GONÇALVES, R. R. Do V.; PINTO, H. S.; ZULLO JUNIOR, J. Relação entre a precipitação e o NDVI em imagens AVHRR/NOAA para a cana-deaçúcar, no estado de São Paulo. Anais Online do XIV Simpósio Brasileiro de Sensoriamento Remoto. Natal, Brasil, 2009, p. 553-560.

BLACKBRIDGE. Satellite Imagery Product Specifications, Version 6.1, April, 2015. Disponível em: <http://blackbridge.com/rapideye/upload/RE_Product_S pecifications_ENG.pdf>, acesso em 03/09/2015. 
CASTRO, A. L. C.; CALHEIROS, L. B.; CUNHA, M. I. R.; BRINGEL, M. L. N. C. Manual de desastres naturais. Brasília: Ministério da Integração Nacional, 2003. 174 p. Disponível em: <http://www.defesacivil.mg.gov.br/conteudo/arquivos/m anuais/Manuais-de-Defesa-Civil/Manual-DesastresNaturais-Vol-1.pdf>. Acesso em: 03/09/2015.

FURTADO, D. A.; BARACUHY, J. G. de V.; FRANCISCO, P. R. M.; FERNANDES NETO, S.; SOUSA, V. A. de. Tecnologias Adaptadas para o Desenvolvimento Sustentável do Semiárido Brasileiro. V.01, 308 p. ISBN 978-85-60307-10-4. Campina Grande: EPGRAF, 2014.

INSA - Instituto Nacional do Semiárido. Sinopse do Censo Demográfico para o Semiárido Brasileiro. Salomão de Sousa Medeiros...[et al] - Campina Grande: INSA, 2012. 103 p. ISBN: 978-85-64265-04-2.

MOREIRA, A. A.; GUASSELLI, L. A.; SILVA FILHO, L. C. P. da; ANDRADE, A. C. F. de; ARRUDA, D. C. de. Índice de Condição de Vegetação (VCI) para mapeamento de seca no Norte do Estado de Minas Gerais. Anais Online do XVII Simpósio Brasileiro de Sensoriamento Remoto. João Pessoa, 2015.

PONZONI, F. J.; SHIMABUKURO, Y. E.; KUPLICH, T. M. Sensoriamento Remoto da Vegetação. 2 Ed. atualizada e revisada. ISBN 978-85-7975-053-3. São Paulo: Oficina de Textos, 2012.

R-PROJECT.The $\mathrm{R}$ Project for Statistical Computing.Disponível em <https://www.r-project.org/>, acesso em 03/09/2015.
RIOS, I. Q.; VALE, R. de M. C. do. NDVI como subsídio para o estudo do processo de desertificação na bacia hidrográfica do Rio Vaza-Barris - Bahia. Anais do Simpósio Regional de Geoprocessamento e Sensoriamento Remoto - GEONORDESTE. Aracaju, 2014.

ROUSE, J. W.; HAAS, R. H.; SCHELL, J. A; DEERING, D. W. 1974. "Monitoring vegetation systems in the great plains with ERTS", Proceedings, Thrid Earth Resources Technology Satellite-1 Symposium, Greenbelt: NASA SP-351, 3010-3017.

SILVA, V. C. B.; MACHADO, P. de S. SIG na análise ambiental: susceptibilidade erosiva da bacia hidrográfica do córrego Mutuca, Nova Lima - Minas Gerais. Revista de Geografia. v. 31, n. 2, UFPE: 2014.

SOUSA JÚNIOR, M. de A.; LACRUZ, M. S. P. Sensoriamento remoto para seca/estiagem. In: SAUSEN, T. M.; LACRUZ, M. S. P. Sensoriamento Remoto para Desastres. São Paulo: Oficina de Textos, 2015. Cap. 6, p. 149-174.

USGS - United States Geological Survey. Shuttle Radar Topography Mission - SRTM: Mapping the world in 3 dimensions, 2000. Disponível em: <http://srtm.usgs.gov/index.php>. Acesso em 03/09/2015.

USU - Utah State University. TauDEM - Terrain Analysis Using Digital Elevation Models, Version 5, 2015.Disponível em: <http://hydrology.usu.edu/taudem/taudem5/>. Acesso em 03/09/2015. 